\section{DO ISAAC DE JOÃO CASSIANO AO ISAAC DE NÍNIVE: PROCESSOS DE INCORPORAÇÃO TEXTUAL NA TRADIÇÃO LATINA}

\author{
César Nardelli Cambraia* \\ Recebido em: 04/08/2018 \\ Aprovado em: 28/09/2018
}

\begin{abstract}
RESUMO: A tradição textual da obra de Isaac de Nínive tem como aspecto saliente diferentes casos de incorporação textual (adição de textos de um autor à tradição textual de outro autor). Estudos prévios apresentam como explicação para casos desse tipo a afinidade temática e a contiguidade material, mas a tradição da obra de Isaac de Nínive sugere haver ainda outra motivação pertinente: a semelhança onomástica. No presente estudo analisa-se o processo de incorporação textual de um capítulo das Colações de João Cassiano à tradição textual latina da obra de Isaac de Nínive. A força de atração textual que a obra de Isaac exerceu ao longo de sua tradição decorreria de um movimento de reconstrução do conhecimento acerca do autor.
\end{abstract}

PALAVRAS-CHAVE: Língua latina; Isaac de Nínive; João Cassiano; Crítica textual.

\section{FROM JOHN CASSLAN'S IS AAC TO ISAAC OF NINEVEH: PROCESSES OF TEXTUAL INCORPORATION IN THE LATIN TRADITION}

\begin{abstract}
The textual tradition of Isaac of Nineveh's work has as salient aspect different cases of textual incorporation (addition of texts of one author to the textual tradition of another author). Previous studies have provided as explanation for such cases thematic affinity and material contiguity, but the tradition of Isaac of Nineveh's work suggests that there is another pertinent motivation: onomastic similarity. In the present study, we analyze the process of textual incorporation of a chapter of John Cassian's Collations to the Latin textual tradition of Isaac of Nineveh's work. The force of textual attraction that the work of Isaac exerted throughout its tradition would come from a movement of reconstruction of the knowledge about the author.
\end{abstract}

KEYWORDS: Latin language; Isaac of Nineveh; John Cassian; textual criticism.
* Professor Titular de Filologia Românica, Faculdade de Letras, Universidade Federal de Minas Gerais. nardelli@ufmg.br 


\section{INTRODUÇÃO}

$\mathrm{U}$

ma tradição textual notavelmente rica é a da obra de Isaac de Nínive, não só pela amplitude de sua difusão (por línguas, lugares e épocas), mas também por apresentar diferentes processos relacionados à transmissão de textos. Constitui interessante contribuição para a crítica textual analisar detalhadamente cada um desses processos.

A incorporação textual, entendida aqui como adição de textos de um autor à tradição textual de outro autor, foi comum na tradição textual da obra de Isaac de Nínive. É curioso que, em manuais tradicionais de crítica textual clássica (Fränkel, 1983 [1964]; Reynolds; Wilson, 1995 [1968]; West, 2002 [1973]), praticamente nada se fale sobre esse tema, embora receba certa atenção na crítica textual neotestamentária (Metzger, 1992 [1964]; Aland; Aland, 1995 [1981]).

Apresenta-se aqui a análise de uma incorporação textual específica (um capítulo das Colações de João Cassiano na tradição textual da obra de Isaac de Nínive), com o objetivo de melhor entender como se deu o referido processo.

\section{ISAAC DE NÍNIVE: AUTOR E OBRA ${ }^{1}$}

Isaac de Nínive nasceu em Bet Qatraye (no atual Catar) e foi ordenado bispo de Nínive no monastério de Bet 'Abe (no norte de atual Iraque) por Jorge, o Católico, em 676 d.C. Cinco meses depois, renunciou ao cargo e foi viver como anacoreta na montanha de Matut, na região de Bet Huzaye (na atual província do Cuzistão no Irã). Posteriormente, transferiu-se para o monastério de Rabban Shabur (também no atual Irã, talvez próximo a Shushtar), onde aprofundou seus conhecimentos das Sagradas Escrituras. Morreu cego e com idade avançada aproximadamente em 700 d.C. e foi sepultado no próprio monastério de Rabban Shabur (Brock, 1999-2000).

Chialà (2002, p. 66-83) considera que estariam entre as obras genuínas três conjuntos de capítulos e dois fragmentos de outra coleção. A Primeira Parte é composta de 82 capítulos; a Segunda Parte compõe-se de 41 capítulos (dos quais o $16^{\circ}$ e o $17^{\circ}$ correspondem respectivamente ao $54^{\circ}$ e ao $55^{\circ}$ da Primeira Parte); a Terceira Parte apresenta 17 capítulos (dos quais o $14^{\circ}$ e o $15^{\circ}$ correspondem respectivamente ao $22^{\circ}$ e ao $40^{\circ}$ da Primeira e o $17^{\circ}$ corresponde ao $25^{\circ}$ da Segunda); a Quarta Parte não é conhecida; a Quinta Parte compreende apenas dois fragmentos próprios. Vê-se que, conjuntamente, a obra de Isaac compreende pelo menos 137 capítulos distintos.

Dessas coleções importa aqui especificamente a Primeira Parte: do original em siríaco foi traduzida para o grego em fins do séc. VIII ou princípios do séc. IX por dois monges Patrikios e Abramios - do mosteiro de Mar Sabbas, situado próximo a Jerusalém, e do grego para o latim por volta de fins do séc. XIII. Considerando que a maioria dos manuscritos

\footnotetext{
${ }^{1}$ A síntese desta seção baseia-se em Cambraia e Avellar (2017, p. 17-8).
} 
com a tradução latina é dos sécs. XIII a XV, que o manuscrito considerado mais antigo (cód. plut. LXXXIX/96, Bibl. Medic. Laur. de Florença) seria do séc. XIII e que a citação mais antiga em latim do texto de Isaac parece estar no Tractatus Pauperis (concluído em 1270) de John Pecham (1230-1292), Chialà (2002, p. 295) propôs o séc. XIII como terminus ante quem para a tradução latina.

\section{INCORPORAÇÃo TEXTUAL E SUAS MOTIVAÇÕES}

Ao tratar de modificações textuais em uma tradição (não raramente chamadas "corrupções" ou "interpolações"), autores de manuais tradicionais de crítica textual sempre mencionam as adições: West (2002, p. 17-35), p. ex., cita casos de adição de versos aos poemas homéricos, de novas seções ao poema geográfico de Dionísio Periegeta e de glosas. Quando aborda alterações em função de considerações doutrinárias, Metzger (1992 [1964], p. 201-6) apresenta explicações interessantes para sua motivação:

The manuscripts of the New Testament preserve traces of two kinds of dogmatic alterations: those who involve the elimination or alteration of what was regarded as doctrinally unacceptable or inconvenient, and those which introduce into the Scriptures 'proof' for a favorite theological tenet of practice. (...) In the view of the increasing emphasis on asceticism in the early Church and the corresponding insistence upon fasting as an obligation laid on all Christians, it is no surprising that monks, in their work of transcribing manuscripts, should have introduced several references to fasting, particularly in connection with prayer. ${ }^{2}$

As modificações na tradição textual da obra de Isaac de Nínive apresentam um padrão diversificado. Como assinalou Wensinck (1969 [1923], p. XIII-XVII), na tradução do siríaco para o grego houve: (a) supressão de 14 dos 82 capítulos, motivada por serem os mais difíceis; (b) adição de 4 capítulos pertencentes a João de Dalyata (ca. 690-ca. 780), para a qual o estudioso não apresenta justificativa; e (c) reordenação dos capítulos em função dos temas tratados (com capítulos sobre o amor colocados juntos, assim como os sobre as tentações, etc.). O referido estudioso chama a atenção também para a particularidade em relação ao nome de autoridades: (a) o nome dos padres da Cítia e dos teólogos do séc. IV foi mantido (Atanásio, Basílio, Efraim, Dionísio Areopagita e Cirilo); (b) o de Evágrio não

\footnotetext{
${ }^{2}$ Tradução minha: “Os manuscritos do Novo Testamento preservam traços de dois tipos de alterações dogmáticas: aquelas que envolvem a eliminação ou alteração do que era considerado doutrinariamente inaceitável ou inconveniente e aquelas que introduzem nas Escrituras a 'prova' de um princípio teológico favorito de prática. (...) Na visão da crescente ênfase no ascetismo na Igreja primitiva e na insistência correspondente no jejum como uma obrigação imposta a todos os cristãos, não é surpreendente que os monges, em seu trabalho de transcrever manuscritos, tenham introduzido várias referências ao jejum, particularmente associado à oração”.
} 
aparece, tendo sido apenas suprimido ou substituído por Nilo, Marcos ou Gregório; (c) o de Teodoro da Mopsuestia foi igualmente apenas suprimido ou substituído por Gregório, João Crisóstomo e Martiniano; e (d) o de Diodoro foi substituído por Dionísio Areopagita ou "por um dos grandes sábios". Wensinck (1969 [1923], p. XVII) explica essa particularidade como intenção de suprimir nomes que não eram aceitos pela igreja monofisista. ${ }^{3}$ Miller (1984, p. XCI) assinala ainda que a tradução grega da obra de Isaac de Nínive incorporou também uma carta de Filóxeno (ca. 450-523) a Patrício. A explicação para essa incorporação dada por Miller (1984, p. XCI), tomando como base o cód. Vatic. Syr. 125, em que os 4 capítulos de João de Dalyata e a carta de Filóxeno se seguem ao texto de Isaac, é a seguinte:

Evidently the Greek translators possessed a manuscript similar to his one and, knowingly or unknowingly, added the Epistle and the selection of John Saba's homilies to the text of Saint Isaac's writings. It is possible that they indicated that these works did not belong to Saint Isaac, and later copyists omitted this information. It is also possible that the manuscript which they possessed was unclear about the authorship of these pieces. ${ }^{4}$

Ainda que 68 dos 82 capítulos da Primeira Parte em siríaco tenham sido traduzidos para o grego, apenas 26 desses 68 foram traduzidos para o latim. Como já foi dito, na tradição grega se agregaram ao texto de Isaac os 4 capítulos de João de Dalyata (ca. 690-ca. 780) e uma carta de Filóxeno. Desses cinco textos, apenas dois de Dalyata passaram para a tradição latina (capítulos 17 e 18 na tradição grega antiga). A esses 28 capítulos (26 de Isaac mais 2 de Dalyata) se agregou à tradição latina um apêndice de origem variada (ora como capítulo autônomo ora como parágrafo final de capítulo): por terem se dedicado especificamente às tradições siríaca e grega, Wensinck (1969 [1923]) e Miller (1984) não terão se dado conta da existência dessa outra incorporação. $O$ apêndice apresenta o seguinte texto, segundo os mss. 572 (f. 38r) e 426 (f. 92v) da Biblioteca do Sacro Convento de Assis (aplicaram-se normas de regularização gráfica na transcrição e as variantes do ms. 426 são apresentadas entre colchetes): ${ }^{5}$

\footnotetext{
${ }^{3}$ No que se refere a Isaac de Nínive, Cambraia (2000, p. 58) assinala que há uma discussão sobre se teria se filiado ao Nestorianismo, vertente da Igreja, representada por Nestório (patriarca de Constantinopla entre 428 e 431), para a qual haveria duas pessoas separadas em Cristo - uma divina e outra humana (“difisista"), opondo-se à doutrina ortodoxa (“monofisista”), para a qual Cristo era uma única pessoa, ao mesmo tempo Deus e homem. Não há consenso sobre sua heterodoxia (Allchin, 1990, p. 9-10).

${ }^{4}$ Tradução minha: "Evidentemente, os tradutores gregos possuíam um manuscrito similar a este e, conscientemente ou não, acrescentaram a carta e a seleção das homilias de João Saba [= João de Dalyata] ao texto dos escritos do Santo Isaac. É possível que eles indicassem que essas obras não pertenciam a Santo Isaac e, mais tarde, os copistas omitiram essa informação. Também é possível que o manuscrito que eles possuíam não tenha sido claro sobre a autoria dessas peças."

${ }^{5}$ Identificação das fontes: (a) Jerônimo, Epistolas, 108, \19 (PL, vol. 22, col. 897); (b) Jerônimo, Epistolas, 125, \8 (PL, vol. 22, col. 1076); (c) Jerônimo, Epistolas, 125, \ 11 (PL, vol. 22, col. 1078); (d) Jerônimo, Epistolas, 125, \11 (PL, vol. 22, col. 1078); (e) Jerônimo, Epistolas, 125, \ 7 (PL, vol. 22, col. 1076); (f)
} 
Nunquam de ore monachi turpis aut lascivus sermo egrediatur. In hiis enim signis libidinosus animus ostenditur, et per exteriorem hominem interioris hominis vitia demostrantur ${ }^{(a)}$. Monachus non desideret verborum frequentiam, que de singularitate censentur ${ }^{(b)}$. Monachus sit vigil sensibus semper, ne vanis cogitationibus polluatur ${ }^{(c)}$. Amet scientiam Scripturarum, et carnis scientiam [426: scientiam vel vitia] non amabit ${ }^{(\mathrm{d})}$. Monachus qui Christum desiderat nihil aliud dignatur aspicere ${ }^{(e)}$, sed per paradisum variarum Scripturarum poma decerpit ${ }^{(\mathrm{f})}$. Hiis utitur delitiis : harum fruitur amplexu. Monachus habeat columbe simplicitatem, nec cuiquam machinetur dolum ${ }^{(\mathrm{g})}$. Vita hominis sapientis est meditatio mortis ${ }^{(\mathrm{h})}$. Tunc quisque in se [426: se quisque] monachum judicet, cum se minimum extimaverit cunctis ${ }^{(i)}$. Pallor enim cum humilitate et macies in facie decus est monachi ${ }^{(j)}$. Si potueris injuriari et affici contumeliis et portare et tahore [426: sine rachore], ${ }^{6}$ magna est hec res et super omnia alia effectem [426: efficere] mandata ${ }^{(k)}$. Monachus enim [426: omite] qui in terra possessionem querit monachus non est $^{(1)}$. Omnis qui secundum Deum est sapiens est et beatus est ${ }^{(m)}$. Beata communio divinitatis et cognitio virtus boni operis est $\mathrm{t}^{(\mathrm{n})}$. Deo gratias. Amen.

Esse apêndice apresenta duas características interessantes. Primeiramente, enquadrase no padrão assinalado por Metzger (1992 [1964], p. 206) de adição, pelos monges copistas, de textos com referência a aspectos do asceticismo, tema que já era o cerne da obra de Isaac de Nínive. Em segundo lugar, confirma a interpretação de Miller (1984, p. XCI) sobre o processo de incorporação: um texto que se segue a outro acaba sendo incorporado como se fosse do primeiro.

Considerando os testemunhos manuscritos da tradição latina ${ }^{7}$ consultados com o texto integral (24 manuscritos) da obra de Isaac de Nínive, verificam-se três padrões: (a) ausência do apêndice; ${ }^{8}$ (b) apêndice depois do explicit com o título da obra de

Jerônimo, Epistolas, 125, \ 7 (PL, vol. 22, col. 1076); (g) Jerônimo, Epístolas, 58, \6 (PL, vol. 22, col. 584); (h) Jerônimo, Epistolas, 60, \14 (PL, vol. 22, col. 598); (i) Isidoro, Sentenças, liv. 3, capítulo 19, $\int 1$ (PL, vol. 83, col. 694); (j) Jerônimo, Epistolas, 22, \17; 24, \5; ou 45, \5 (PL, vol. 22, col. 404, 428 ou 481); (k) Rufino, De Vitis Patrum, III, \85 (PL, vol. 73, col. 775); (1) Gregório, Diálogos, liv. 3, capítulo 14 (PL, vol. 77, col. 245); (m) Isidoro, Sentenças, liv. 2, capítulo 1, \1 (PL, vol. 83, col. 599); (n) Isidoro, Sentenças, liv. 2, capítulo 1, \1 (PL, vol. 83, col. 599).

${ }^{6}$ Neste ponto, há na fonte, De Vitis Patrum de Rufino, a lição et tacere.

${ }^{7}$ A tradição textual latina da obra de Isaac de Ninive encontra-se atualmente distribuída em 103 manuscritos supérstites (54 integrais; 44 não integrais, de fragmentos ou abreviamentos; 5 de extensão ainda não identificada) e 12 edições impressas (Cambraia, 2015, com atualizações aqui).

814 manuscritos: Bibl. Pinacoteca Accademia Ambrosiana, Milão, A 49 sup., séc. XIII, f. 75v14; Bibl. Città di Arezzo, Arezzo, 311, séc. XIII ex.-XIV in., f. 371v25; Nár. Knih., Praga, X A 2, séc. XIV, f. 105va29; Nár. Knih., Praga, X G 8, séc. XIV, f. 130va43; Universitätsbibl., Basileia, B IX 7, séc. XIV.2, 
Isaac; ${ }^{9}$ e (c) apêndice antes desse explicit. ${ }^{10} \mathrm{O}$ padrão de ausência tem interpretação ambígua: pode não haver o apêndice porque ainda não tinha sido incorporado à tradição na época da cópia do testemunho ou porque o copista optou por não copiar (seja porque estava marcado que o apêndice não pertencia à obra de Isaac, seja porque quis abreviar a cópia), o que torna esse padrão pouco elucidativo. Já os padrões de (b) e (c) são mais esclarecedores, porque expressam os diferentes passos do processo de incorporação. No caso de (b), em que o apêndice aparece depois do explicit com o título da obra de Isaac (com marcação clara, portanto, de que ele não pertence à obra de Isaac), ter-se-ia a primeira fase, indicando assim vínculo a um segundo ramo da tradição, intermediário. No caso de (c), em que o apêndice aparece antes desse explicit (com marcação clara, portanto, de que ele é tratado como parte da obra de Isaac), ter-se-ia a segunda fase, indicando assim vínculo a um terceiro ramo da tradição, mais inovador.

A época de aparecimento do apêndice parece ser princípios do séc. XIV: já está no manuscrito 572 da Bibl. do S. Convento de Assis, datado de 1310-1312, no qual aparece após o explicit com o título. O momento de sua incorporação parece ser também no séc. XIV: há três manuscritos dessa época com a incorporação. ${ }^{11}$ Está também presente no ms. Plut. LXXXIX/96 da Bibl. Med. Laur. (Florença), a que se atribui a data de séc. XIII (Bandini, III, 1776, p. 349), mas esta datação não parece proceder, pois o volume de erros acumulados que a cópia apresenta é comparável apenas ao dos mss. lat. class. II 61 da Bibl. Marciana (Veneza), séc. XIV, e alc. 387 da Bibl. Nac. (Lisboa), de 1409: é bem provável que o referido manuscrito Plut. LXXXIX/96 seja do séc. XIV, e não do XIII. Assinale-se ainda que, nesse manuscrito dito do séc. XIII, o apêndice aparece incorporado (antes do explicit), enquanto os manuscritos mais antigos com o apêndice não incorporado (depois do explicit) são do séc. XIV, o que novamente sugere ser esse manuscrito mais tardio do que se afirma.

O exemplo da incorporação do apêndice na tradição textual da obra de Isaac de Nínive é relevante para atestar que os padrões de incorporação descritos por Metzger (1992 [1964]) e Miller (1984) são capazes de dar conta dessa particularidade da tradição em estudo. Na próxima seção, em que se tratará do principal objeto deste estudo, demonstrar-se-á que

f. 220vb37; Bibl. Nac., Madri, 307, séc. XIV-XV, f. 130v22; Stadtbibl. und Stadtarch, Trier, 717/272, a. 1401, f. 263r2; Universitätsbibl., Basileia, O II 13 [Nr. 2], a. 1407, f. 71v7; Universitätsbibl., Basileia, A IX 91, a. 1468, f. 147r30; Bibl. de l'Arsenal, Paris, 499, séc. XV, f. 184v27; Stiftsbibl., Melk, 1838, séc. XV, f. 292r25; Stiftsbibl., Melk, 653, séc. XV, f. 347v16; Nár. Knih., Praga, DE II 32, XIV G 5, séc. XV, f. 43va28; e Universitätsbibl., Leipzig, 347, séc. XV, f. 63r19.

93 manuscritos: Bibl. S. Convento, Assis, 572, a. 1310-1312, f. 38ra5; Bibl. S. Convento, Assis, 426, séc. XIV, f. 92v8; e Museu Episcopal, Vic, 55, a. 1457, f. 151r13.

107 manuscritos: Bibl. Med. Laur., Florença, Plut. LXXXIX/96, séc. XIII, f. 48r18; Universitätsbibl., Basileia, B IX 11, séc. XIV, f. 158ra18; Bibl. Públ., Palma de Mallorca, 529, séc. XIV, f. 189v23; Bibl. Marciana, Veneza, lat. class. II 61, séc. XIV, f. 44va24 ; Bibl. Nac., Lisboa, alc. 387, a. 1409, f. 115v39; Bibl. Mazarine, Paris, 659, séc. XV, f. 102r24; e Bibl. Públ., Tarragona, 135, séc. XV, f. 94r21.

${ }^{11}$ Universitätsbibl., Basileia, B IX 11; Bibl. Públ., Palma de Mallorca, 529; e Bibl. Marciana, Veneza, lat. class. II 61, séc. XIV, f. 44va24. 
os referidos padrões de incorporação não explicam um caso específico: o da incorporação de um capítulo da obra de João Cassiano na tradição textual de Isaac de Nínive.

\section{Do ISAAC DE JOÃo CASSIANO AO ISAAC DE NÍNIVE}

Uma comparação entre a tradução latina da obra de Isaac de Nínive com o texto genuíno vinculado diretamente à tradição siríaca revela a existência de uma porção de texto presente naquela, mas ausente nesta (aqui representada pela tradução inglesa de Wensinck (1969 [1923]), feita a partir do texto siríaco editado por Bedjan (1909)): trata-se de uma seção que ocorre no interior do capítulo organizado de forma dialógica, com perguntas e respostas. Na numeração do texto siríaco de Bedjan (1909), esse capítulo dialógico é o capítulo 45 (bem como na sua tradução para o inglês de Wensinck (1969 [1923], p. 152-80), mas na numeração adotada por Miller (1984, p. 163-86) em sua tradução para o inglês baseada sobretudo na tradução grega, trata-se do capítulo 37. Essa porção de texto não tem correspondência na tradição siríaca (Wensinck (1969 [1923], p. 165) nem na grega (Miller, 1984, p. 175).

Uma busca quanto à origem do referido excerto revelou que se trata do capítulo 30 da $9^{a}$ colação de João Cassiano (Petschenig, 1886, p. 276-7).

Nota-se de imediato que uma das explicações para a incorporação de textos à tradição da obra de Isaac de Nínive já apresentada anteriormente não se aplicaria aqui: a interpretação de que a seção incorporada se seguia ao fim do texto genuíno e passou a ser considerada como parte dele (como se deu, na tradição siríaca, com os quatro capítulos de João de Dalyata e a epístola de Filóxeno, e, na tradição latina, com o já mencionado apêndice) não é possível, porque a incorporação se deu diretamente no interior do texto, e não no fim.

Dos 24 manuscritos consultados com o texto integral, apenas 10 apresentam a incorporação do capítulo de João Cassiano. ${ }^{12}$ Os testemunhos consultados mais antigos com sua incorporação são do séc. XIV ${ }^{13}$

Diferentemente da explicação dada por Metzger (1992 [1964]), baseada na ideia de afinidade temática, e da explicação de Miller (1984), baseada na ideia de contiguidade material, deve-se aqui postular outra explicação para a incorporação do texto de João Cassiano na obra de Isaac de Nínive: semelhança onomástica.

A razão pela qual houve a referida incorporação está relacionada ao fato de, na obra de João Cassiano, haver um interlocutor chamado Isaac. Do ponto de vista histórico, é óbvio que Cassiano (sécs. IV-V) não se referiu a Isaac de Nínive (séc. VII), mas sim provavelmente a Isaac de Antioquia (séc. V). Mas, na baixa Idade Média, não parecia haver clareza sobre os diferentes Isaacs. Prova disso é que, em alguns manuscritos com a obra de Isaac de

\footnotetext{
${ }^{12}$ Nár. Knih., Praga, X G 8, séc. XIV, f. 112va16; Universitätsbibl., Basileia, B IX 11, séc. XIV, f. 142vb18; Nár. Knih., Praga, X A 2, séc. XIV, f. 86va4; Stadtbibl. und Stadtarch, Trier, 717/272, a. 1401, f. 249va13; Stiftsbibl., Melk, 1838, séc. XV, f. 231r23; Nár. Knih., Praga, DE II 32, XIV G 5, séc. XV, f. 18va16; Universitätsbibl., Leipzig, 347, séc.XV, f. 24r10; Stiftsbibl., Melk, 653, séc. XV, f. 312v2; Bibl. Mazarine, Paris, 659, séc. XV, f. 39r25; Bibl. Públ., Tarragona, 135, séc. XV, f. $50 v 2$.

${ }^{13}$ Nár. Knih., Praga, X G 8; Nár. Knih., Praga, X A 2; e Universitätsbibl., Basileia, B IX 11.
} 
Nínive, ${ }^{14}$ reproduz-se o capítulo 14 do livro terceiro dos Diálogos de São Gregório (sécs. VIVII), intitulado De Isaac servo Dei (PL, v. 77, col. 244), ${ }^{15}$ em que Gregório narra a vida de um Isaac que teria ido da Síria à Itália, certamente Isaac de Antioquia. Naturalmente a aposição desse capítulo à obra de Isaac de Nínive é sinal de que os copistas consideravam serem ambos o mesmo religioso. Também junto à obra de Isaac de Nínive aparece eventualmente ${ }^{16} \mathrm{um}$ prólogo em que se fala que o Isaac em questão seria aquele que teria sido mencionado por João Clímaco (ca. 579-649), como se vê no $4^{\circ}$ degrau de sua Escada Celestial (PL, v. 88, col. 703), que, novamente, só poderia ter sido o Isaac de Antioquia (séc. V).

Essa semelhança onomástica deriva do fato de, nos manuscritos medievais, Isaac de Nínive ser identificado simplesmente como Isaac de Syria ou forma semelhante no título da obra, ${ }^{17}$ o que, a rigor, seria aplicável de fato tanto a Isaac de Nínive como a Isaac de Antioquia, já que ambos estiveram na região da Síria. Essa questão onomástica tem apresentado repercussão inclusive para o processo de recensão de sua obra na tradução latina:

A identificação dos testemunhos manuscritos tem sido bastante trabalhosa em função de variações no nome do autor e no nome da obra. As variações no nome do autor estão relacionadas a dois problemas: (a) falta de uniformidade na nomeação do mesmo autor e (b) confusão entre diferentes autores chamados Isaac. No primeiro caso, verificam-se, nos catálogos que registram os testemunhos latinos, distintas formas de nomear o aqui chamado Isaac de Nínive: encontram-se designações como Isaacus Syrus Junior, Isaac de Syria; Isaac, abbas Syriae. Se não bastasse esse problema, contribui ainda para a dificuldade em questão a confusão entre diferentes Isaacs, autores de obras religiosas: Isaac da Antioquia (séc. V), Isaac de Nínive (séc. VII), Isaac de Estela (séc. XII).

(Cambraia, 2005, p. 8)

Para dar a conhecer qual é o excerto em questão, apresenta-se abaixo sua transcrição com base na edição crítica das Colaçoes de João Cassiano realizada por Petschenig (1886, p. 276-277) e com base na tradição manuscrita da obra de Isaac de Nínive, com marcação em negrito das principais lacunas entre as duas versões:

\footnotetext{
${ }^{14}$ Universitätsbibl., Basileia, B IX 11, séc. XIV, f. 158rb1; Universitetsbibl., Uppsala, C 631, depois de 1419 , f. 334v1.

${ }^{15}$ Cabe ressaltar que, embora esse capítulo de São Gregório não tenha sido incorporado à obra de Isaac de Nínive como se dela fosse parte, uma frase desse capítulo consta do já referido apêndice que foi posteriormente incorporado: cf. item (l) do apêndice reproduzido acima.

16 Bibl. Nac. (Lisboa), alc. 387, a. 1409, f. 95rb1.

${ }^{17}$ P. ex.: Incipit liber abbatis Y saac de Syria (Bibl. Públ., Palma de Mallorca, 529, séc. XIV, f. 140r1); Incipit libellus abbatis Y saac Syrie de acessu anime ad Deum qui creavit illam (Universitätsbibl., Basileia, B IX 11, séc. XIV, f. 133ra1-2); Liber beati Ysaac syri uiri religiosi compositus in sermonibus quadraginta de contemplationis perfectione (Bibl. Pinacoteca Accademia Ambrosiana, Milão, A 49 sup., séc. XIII, f. 1r1-2).
} 


\begin{tabular}{|c|c|}
\hline & $\begin{array}{c}\text { Excerto da edição crítica } \\
\text { das Colações de João Cassiano }{ }^{18}\end{array}$ \\
\hline & $X X X$. Ab his ergo lacrimis multum distant illae \\
\hline & quae obdurato corde de siccis oculis exprimuntur. \\
\hline & quas licet non penitus infructuosas esse credamus \\
\hline & (bono enim proposito earum adtemptatur emissio, \\
\hline & abhis praesertim quinecdumueladscientiam \\
\hline & peruenire perfectam uel pristinorum seu \\
\hline & praesentium uitiorum potuerunt ad purum \\
\hline & labe mundari), ab his tamen qui in affectum iam \\
\hline & transiere uirtutum nequaquam debet hoc modo \\
\hline & extorqueri profusio lacrimarum nec exterioris \\
\hline & bominis magno opere adfectandi sunt fletus, qui \\
\hline & etiamsi fuerint utcumque producti, numquam \\
\hline 13 & pertingere illam spontanearum lacrimarum \\
\hline 14 & poterunt ubertatem. magis enim supplicantis \\
\hline & animum suis conatibus detrahentes bumiliabunt \\
\hline & atque ad humana demergent et ab illa caelesti \\
\hline & sublimitate deponent, in qua adtonita mens orantis \\
\hline & indeclinabiliter debet esse defixa, eamque \\
\hline 1 & conpellent precum suarum intentione \\
\hline & erga steriles et coacticias lacrimarum guttulas \\
\hline & \\
\hline
\end{tabular}

Excerto das Colações de João Cassiano na tradição manuscrita de Isaac de Nínive

Isaac: A lacrimis compassionis vel devotionis celestium multum distant ille que ob corde siccis lacrimis exprimuntur, quas licet non penitus infructuosas credamus esse: bono enim proposito earum attendatur emissio. Ab biis tamen qui in affectum jam transiere virtutum nequaquam debet boc modo extorqueri profusio lacrimarum nec exterioris hominis magno opere affectandi sunt fletus, qui etiamsi fuerint ubicumque producti nunquam pertingere illam spontanearum lacrimarum poterunt ubertatem. Magis enim supplicantis animum conatibus suis distrahentes bumiliabunt, atque ad bumana demergunt, et ab illa celesti sublimitate deponent, in qua attonita mens orantis indeclinabiliter debet esse defixa, eamque compellunt precum suarum intentione laxata erga steriles et coactitias lacrimarum guttulas egrotare. $^{19}$

Variantes no excerto das Colações de João Cassiano na tradição manuscrita de Isaac de Nínive ${ }^{20}$

1. Isaac] DE II 32 Isaac verumtamen, 347 Iscc / / 2. multum] X G 8 multam, DE II 32 non multum / / 3. ob corde] B IX 11 ob [espaço em branco] corde X G 8, X A 2, 717/272, 1838, 347, 653 a corde; DE II 32 obduratione cordis, 659, 135 ob Dominum sicco corde; siccis] 135 de siccis // 4. non] 347 omissit; penitus infructuosas] X G 8, X A 2, 1838, 653 infructuosas penitus // 4-5. credamus esse] 659, 135 esse credamus // 5. bono enim] X A 2 enim bono; earum] 659 eorum, 135 eorum com correção para earum por outro punho na margem; attendatur] 659, 135 attemptatur // 6. affectum] 659 affectu; jam] X G 8 omissit // 8. nec] X G 8 ne // 9. magno opere] X G 8, 717/272, 1838, 653, 659 magnopere // 10. ubicumque] 717/272 ubique, 659 utcumque, 135 utrumque com nota por outro punho na margem dizendo alias utique vel utrimque // 11. illam] X G 8, XA2, 717/272, 1838, 347, 653 ad illarum, DE II 32 illarum, 135 ad illam // 12. poterunt 135 potuerunt com primeiro $u$ subpontilhado // 13. ubertatem] 717/272 libertatem; supplicantis] DEII32 supplicant // 14. conatibus suis] 659, 135 suis conatibus // 15. atque] 347 adque; demergunt 659, 135 demergent // 16. et] X G 8 atque; deponent] DE II 32 deponunt // 18. defixa] DE II 32 fixa; compellunt] 659, 135 compellent // 19. laxata] X G 8, 717/272, 1838, DE II 32, 347 laxatam, 653 omissit; erga] XG8 go, DE II 32 gratia // 20. coactitias] DE II 32 coactivas, 659 coaetitias.

\footnotetext{
${ }^{18}$ Petschenig (1886, p. 2) empregou basicamente seis testemunhos na elaboração de sua edição crítica: três integrais (V = Vaticanus 5766, séc. VIII; D = Parisinus, olim Corbeiensis, 13381, séc. IX; W = Verceilensis CLXXXVIL. 44, sécs. IX-X) e três com lições selecionadas $(0=$ Parisinus [nouvelles acquisitions Latines] 2170, séc. IX; X = Sangallensis 574, sécs. IX-X; P = Palatini 560, séc. X). Na edição de Migne (PL, v. 49, coll. 806-807) de 1874, aparentemente baseada na de Leipzig de 1733, o trecho "Ab his...mundari" aparece como final do capítulo 29.
} 
Uma primeira comparação entre o excerto na sua versão da edição crítica e na versão da tradição de Isaac de Nínive revela que esta é mais abreviada (cf. a ausência do trecho ab his... mundari [11. 5-8]). Mas ela apresenta uma inovação: cf. compassionis vel devotionis celestium [11. 1-2]. As variantes na tradição da própria obra de João Cassiano elencadas por Petschenig (1886, p. 276-7) não apresentam de forma geral muito interesse para a presente discussão. Mas a comparação entre as duas versões acima revela um ponto de especial dificuldade no processo de transmissão do texto de Cassiano ao longo da tradição da obra de Isaac: o trecho obdurato corde não aparece como tal na tradição de Isaac de Nínive, mas como diferentes variantes: $o b$ [espaço em branco] corde (BIX11); a corde (XG8, XA2, 717/272, 1838, 347, 653); obduratione cordis (DEII32) e ob Dominum sicco corde $(659,135)$. A grande proximidade de DEII32 com a forma genuína poderia sugerir que apresentasse o texto mais próximo do genuíno de forma geral mesmo não sendo dos mais antigos (é do séc. XV frente a outros do séc. XIV), mas abundam nele variantes que afastam da forma genuína em outros pontos: cf. especialmente Isaac verumtamen por Isaac; non multum por multum; illarum por illam; supplicant por supplicantis; deponunt por deponent e gratia por erga.

A razão de o excerto em questão na obra de Isaac de Nínive começar pelo nome Isaac certamente é uma reminiscência do padrão do texto de origem: como a $9^{a}$ colação de João Cassiano envolve manifestação de três locutores (João Cassiano [no proêmio], seu amigo Germano e Isaac), no início de cada mudança de locutor indica-se de quem se trata (só nos casos de Germano ou Isaac). O capítulo 28 tem como locutor Germano e os capítulos 29 a 32 são de Isaac. Na edição de Petschenig (1886), aparece o nome de Isaac apenas no início do capítulo 29 (no que se refere aos capítulos 29 a 32), mas o que adentrou a tradição de Isaac de Nínive é o capítulo 30: pode-se aventar a hipótese de que a cópia do texto de Cassiano que serviu de modelo para a transcrição do monge interpolador indicasse em cada capítulo quem era o locutor, mesmo se se tratasse do mesmo do capítulo anterior.

Retomando uma das principais questões da presente discussão, a motivação para a presença do excerto de João Cassiano na obra de Isaac de Nínive seria a semelhança onomástica, pois há menção de um Isaac na obra de Cassiano. Mas por que Isaac, o de Antioquia, está na obra de Cassiano?

Como assinala Silva (2014, p. 107), as Colações de Cassiano abarcam diálogos com vários dos chamados Padres do Deserto:

As Conferências dos anciãos ou Conlationes, segundo a terminologia do dicionário Patrístico ou ainda Conlationes Patrum (Conferências dos Pais) ou Collationes são relatos ascético-místicos, "conversações mais ou menos fictícias" (...), provenientes de entrevistas com alguns célebres Pais do deserto, tanto do Egito como da Palestina, tratando dos mais diversos assuntos sobre espiritualidade, a vida e as virtudes que devem ser praticadas por um monge. (...) Como um verdadeiro itinerário espiritual, as Conferências dos anciãos contêm instruções referentes aos primeiros passos da conversão do monge e seguem instruindo até os momentos referentes à vida contemplativa em seus graus mais elevados. Elas enfocam o "homem interior", homo interior, 
segundo a expressão do próprio Cassiano, presente no prefácio das primeiras Conferências.

Especificamente sobre o aspecto que teria feito Cassiano tratar de Isaac em suas Colações, esclarece Silva (2014, p. 120-1):

Vale lembrar que, no final do primeiro bloco de conversações espirituais com os monges de C[1] tia, no caso com o abade Isaac, é feita uma riquíssima exposição sobre a oração e seus estádios até a chegada à oração contemplativa. (...) Dividida em dois blocos, a exposição sobre a oração é um modo pedagógico de ensinar a necessidade da oração contínua e os meios para adquiri-la. (...) Em sua obra, percebemos que João Cassiano não estava simplesmente preocupado em narrar o estilo de vida de alguns ascetas coptas cenobitas ou eremitas, tão pouco desejoso de contar uma memória de viagens, mas em fornecer meios para o crescimento espiritual dos que almejam vida teologal. Suas entrevistas pretendem fundamentar sua doutrina, que ele enriquece com a contribuição de outros mestres e ascetas doutos, sobretudo da escola de Alexandria, como Evágrio Pôntico e Orígenes, cuja teologia e doutrina monástica aparecem nos ensinamentos dos Pais do deserto por ele mencionados.

Considerando o conteúdo da obra de Isaac de Nínive, tão fortemente ancorado na questão da ascese e da explanação de seus estágios (segundo ele, conversão corporal, conversão da alma e conversão espiritual), com especial atenção à questão da oração, não surpreende que os leitores da Idade Média estabelecessem uma identidade entre Isaac de Antioquia, citado por João Cassiano, e Isaac de Nínive.

Um segundo aspecto relativo à incorporação do excerto de Isaac de Antioquia de Cassiano na obra de Isaac de Nínive, além da semelhança onomástica, refere-se a um tema tratado por Metzger (1992 [1964]): a afinidade temática. A razão de a incorporação em questão ter-se dado no meio da obra deve-se a isso: é justamente em uma seção da obra de Isaac de Nínive em que ele trata da questão das lágrimas que foi inserido o excerto derivado da obra de Cassiano, no qual também se fala de lágrimas.

O excerto em questão foi inserido após um trecho em que Isaac de Nínive fala de diferentes tipos de lágrimas:

Lacrimarum quedam sunt adurentes et quedam impinguantes. Omnes autem lacrime que ex corde procedunt propter peccata desiccant corpus et ure[?], ${ }^{19}$ et multotiens ipsum cerebrum sentit in ipsarum exitu lesionem; et primo quidem ad hunc ordinem lacrimarum ex necessitate occurrit homo, et per eas aperitur sibi hostium intrandi secundum ordinem meliorem, quod est gaudium in quo recipit misericordiam. Hec namque sunt lacrime que ab intellectu

\footnotetext{
${ }^{19}$ Consta urunt no ms. 717/272 da Stadtbibl. und Stadtarch. (Trier), a. 1401, f. $243 v a 3$.
} 
profluunt, que corpus decorant pariter et impinguat et sine violentia per semet ipsas emanant, et aspectus hominis alteratur, sicut dicitur: "Letificati cordis facies viret". ${ }^{20}$

Chama a atenção em relação a esse trecho o fato de, nos testemunhos mais antigos consultados, ${ }^{21}$ aparecer uma subdivisão singular no capítulo em questão: como já foi dito antes, a incorporação se dá em um capítulo dialógico, composto de perguntas e respostas. Mas abre-se no meio desse capítulo uma subdivisão só para tratar das lágrimas, com o título mais corrente de "De Differentia Lacrimarum", que parece remontar à tradição grega, pois aparece como tal na tradução de Miller (1984, p. 175), mas não à siríaca, já que não aparece como subdivisão na tradução de Wensinck (1969 [1923], p. 165). Na edição de Petschenig (1886, p. 249), os capítulos 29 e 30 apresentam como título, respectivamente, "Responsio de diuersitate conpunctionum quae per lacrimas digeruntur" e "De eo quod elici non debeant lacrimae, quando non spontaneae proferuntur”, mas, na edição de Migne (1874, col. 804806) os títulos são "Responsio de diversitate spiritualium lacrymarum" e "Quod elici non debeant lacrymae quando non spontaneae proferuntur". Percebe-se que o título do capítulo 29 da edição de Migne (1874) tem maior semelhança com o título que aparece na obra de Isaac de Nínive do que com a tradição mais antiga da obra de Cassiano (reconstituída por Petschenig): isso sugere que os copistas medievais terão usado cópias mais recentes e coevas como modelo para extração do trecho de Cassiano.

Em função do peso que a questão das lágrimas tem na doutrina de Isaac de Nínive, não surpreende que os monges leitores da Idade Média se sentissem estimulados a reunir, na medida do possível, as manifestações sobre tema que considerassem serem do referido autor. A questão das lágrimas interpretada em um quadro mais amplo é assim explicada por Cândolo (2002, p. 58-60):

A Vulgata (...) usará o termo compunctio (...), de onde origina-se o termo consagrado pela tradição, compunção, que será entendido como remorso profundo experimentado no mais íntimo da alma por ter pecado. É esta noção de compunção, associada à prática da ascese, que os Padres do Deserto adotarão e desenvolverão na doutrina do Penthos. Logo, compunção, luto e lágrimas vão ser tão frequentemente associados que passam a ser considerados sinônimos. (...) Mas por que chorar? (...) Isaac [de Nínive] mostra-nos a qualidade do luto e das lágrimas que o cristão deve manifestar: é a morte da alma devida aos pecados cometidos que enluta o cristão e fá-lo lamentar-se; trata-se portanto de um luto espiritual. A compunção é a dor experimentada diante da eminência da morte da própria alma; é uma dor de

\footnotetext{
${ }^{20}$ Transcrito do ms. B IX 11da Universitätsbibl. (Basileia), séc. XIV, f. 142vb5. O trecho entre aspas é citação de Provérbios, 15:13.

${ }^{21}$ Bibl. Pinacoteca Accademia Ambrosiana (Milão), A 49 sup., séc.XIII, f. 29r20; e Bibl. Città di Arezzo (Arezzo), 311, séc. XIII ex.-XIV in., f. 332v3.
} 
arrependimento (pelo já feito) e temor (pelo que poderá suceder). (...) Eis a essência do Penthos: trata-se do luto pela salvação perdida, própria ou de outrem. Todo homem deverá prantear esse luto, pois todo homem é pecador, depois do pecado original de Adão. A expiação dos pecados torna-se, no mundo cristão, a única via a seguir no caminho para a salvação; na prática, essa expiação dá-se não apenas pela penitência mas também pelo Penthos: um sentimento profundo de luto pela alma, expresso com lágrimas.

Especificamente em relação ao Isaac de Antioquia, embora haja menção a lágrimas na sua obra editada por Bickell (1873-1877), tal tema aparece muito acidentalmente, longe da ênfase que Isaac de Nínive lhe dedica. As menções mais relevantes na obra de Isaac de Antioquia parecem ser as seguintes:

Quemadmodum enim oculi, quando lacrimas dolorosas effundunt, chirographum debitorum delent et totum corpus purificant; ita etiam, quando facies procaciter contemplantur, lumen suum amittunt et omnia membra in peccatum inducunt. (BICKELL, 1873, I, p. 255)

Effundamus lacrimas in oratione, ne sanguis noster in regione nostra effundatur! (BICKELL, 1873, I, p. 280-1)

Domine, exaudisti peccatricem lacrimas effundentem; me quoque similiter lacrimantem exaudi! (BICKELL, 1877, II, p. 68)

Lacrimas fundebat in moerore suo, ut per unam potius horam irrideretur, quam per totam aeternitatem ignominiam inveniret. Congregatae sunt passiones ejus dolorosae et convenerunt quasi intercessores, qui in sua perturbatione apud Dominum supplicarent, oculi lacrimis, os fletu altoque planctu, cor denique gemitu mortis. (BICKELL, 1877, II, p. 71)

Lacrimae erant ei pro aqua sancta, oleum suum pro oleo sacramentali, Christus pro sacerdote. (BICKELL, 1877, II, p. 73)

Domine, exaudisti peccatricem lacrimas effundentem; me quoque similiter lacrimantem exaudi ! Amici mei, valde mihi profuit meditatio de hac peccatrice. Dolor mihi irruit et me ad fletum compulit. Lacrimae meae fluxerunt, et ex totis viribus meis illi gratias egi, qui mihi occurrere fecit formam verborum suorum et Scripturam suam, veritatem docentem. (BICKELL, 1877, II, p. 73)

Há, de fato, certos temas comuns entre Isaac de Antioquia e Isaac de Nínive, como a questão do jejum (cf. capítulos 13 e 14 da obra daquele e capítulo 35 da obra deste), ${ }^{22}$

\footnotetext{
22 A numeração de capítulos aqui toma como referência a edição de Bickell (1873-1877) para o Isaac de Antioquia e de Wensinck (1969) para o Isaac de Nínive.
} 
da vigília (cf. capítulo 15 daquele e capítulo 17 deste), das tentações do diabo (capítulo 10 daquele e capítulos 36 deste) e da penitência (cf. capítulo 37 daquele e capítulo 43 deste), mas o tema de lágrima é muito mais saliente em Isaac de Nínive do que em Isaac de Antioquia. Tal constatação faz perceber que as falas de Isaac de Antioquia na obra de João Cassiano (partindo do pressuposto de que o Isaac a que ele se refere seja esse mesmo) estejam mais na esfera da recriação do que da citação, confirmando, como assinalou Silva (2014, p. 107), que as Colações de Cassiano são "conversações mais ou menos fictícias".

\section{Considerações finais}

O processo de transmissão de textos ao longo da Idade Média é sempre complexo, porque está sujeito a intervenções de várias ordens. Especificamente no caso da transmissão da obra de Isaac de Nínive, de alta complexidade em função de sua amplitude, chamam a atenção os diferentes casos de incorporação de textos que não são de sua autoria.

Estudos prévios já haviam assinalado a atuação de fatores como a afinidade temática (METZGER, 1992 [1964]) e a contiguidade material (MILLER, 1984) na transmissão de textos, mas o exame da tradição latina da obra de Isaac de Nínive revelou ter igualmente atuado a semelhança onomástica. Embora se deva admitir que, no caso examinado, em que da obra de João Cassiano foi incorporado texto referente a Isaac de Antioquia na obra de Isaac de Nínive, a afinidade temática (a questão das lágrimas) também deva ter sido relevante, não seria excessivo dizer que terá tido mais peso a questão do nome do que a do tema, pois outros Padres do Deserto trataram da questão das lágrimas, mas seus textos não foram incorporados na tradição de Isaac de Nínive.

Deve-se chamar a atenção para o fato de que a obra de Isaac de Nínive exerceu uma atração textual notável, de forma que trouxe para junto de si, de forma incorporada ou não, diferentes textos. Por um lado, a obra genuína de Isaac de Nínive já se caracterizava por um expressivo número de citações bíblicas e patrísticas, o que significa dizer que já possuía uma força originária de atração. Por outro lado, foram sendo agregados novos textos não genuínos. Primeiramente, há o caso dos capítulos de João de Dalyata e da carta de Filóxeno, que foram integrados à tradição como se fossem de Isaac de Nínive, sob a explicação de Miller (1984) de contiguidade material. A reorganização dos capítulos feita pelos responsáveis pela tradução grega fez com que saíssem do final da obra e se fixassem em seu interior. Em segundo lugar, há o caso do apêndice, composto de 14 proposições de origem diversa, mas sempre versando sobre a questão da conduta esperada para o monge (um caso de afinidade temática). A princípio esse apêndice encontrava-se fora dos limites da obra de Isaac, mas contíguo a ela; em seguida, novamente em função da contiguidade material, foi incorporado como se fosse de Isaac. Em terceiro lugar, houve o caso do capítulo da obra de João Cassiano, cuja motivação para incorporação terão sido a semelhança onomástica e a afinidade temática, diferenciando-se dos dois casos de incorporação citados por ter ocorrido diretamente no interior do texto de Isaac de Nínive. Além desses três casos de incorporação, pode-se mencionar ainda a aposição do capítulo dos Diálogos de São Gregório, no qual tratou 
de um religioso chamado Isaac, capítulo que, nos testemunhos latinos consultados da obra de Isaac de Nínive, não aparece como parte dessa obra.

Se a popularidade de obra de Isaac pode ser associada à crescente valorização do asceticismo ao longo da Idade Média, já a sua força de atração textual pode ser fruto da lacuna de conhecimento sobre o autor. Essa lacuna pode ser explicada de duas formas. Por um lado, a suspeita de filiação de Isaac de Nínive ao nestorianismo e sua visão difisista terá gerado um esforço de apagamento de informação para permitir que sua obra circulasse (basta lembrar dos já citados casos de renomeação de autoridades na obra de Isaac ao longo da tradição). Por outro lado, o fato de haver mais de um Isaac voltado para a vida monástica (Isaac de Antioquia, do séc. V, e Isaac de Nínive, do séc. VII) deve ter propiciado recorrentes casos de informação conflitante, de forma que a resolução teria sido ir apagando toda informação desencontrada. Esses dois processos terão levado a um tal grau de desconhecimento sobre o autor, que posteriormente terá surgido, como reação, um grande empenho em reconstruir sua história e sua tradição textual. A força de atração textual da obra de Isaac de Nínive dever-se-ia a esse movimento de reconstrução.

\section{REFERÊNCIAS}

ALAND, K.; ALAND, B. The text of the new testament: an introduction to critical editions and to the theory and practice of modern textual criticism. 2. ed., rev. and enlarg.. Grand Rapids: Williams B. Eerdmans, 1995.

ALLCHIN, A. M. (Ed.) Selections. English. 1990. Daily readings with St Isaac of Syria. Translated by Sebastian Brock. Springfield, Ill.: Templegate, 1990.

BANDINI, A. M. Catalogus codicum Latinorum Bibliothecae Mediceae Laurentianae. Florentiae: [s. n.], 1774-1777, v. I-IV.

BEDJAN, P. (Ed.) Mar Isaacus Ninivita: de perfectione religiosa. Paris/Leipzig: Otto Harrassowitz, 1909.

BICKELL, G. S. Isaaci Antiocheni, doctoris syriorum, opera omnia. Gissae [Hessen]: J. Rickeri, 1873-1877. $2 \mathrm{v}$.

BROCK, S. From Qatar to Tokyo, by way of Mar Saba: the translations of Isaac of Beth Qatraye (Isaac the Syrian). Aram, n. 11-12, p. 475-84, 1999-2000.

CAMBRAIA, C. N. Livro de Isaac: edição e glossário (cód. alc. 461). 753 f. 2000. Tese (Doutorado em Filologia e Língua Portuguesa) - Faculdade de Filosofia, Letras e Ciências Humanas, Universidade de São Paulo, São Paulo, 2000.

CAMBRAIA, C. N. Contributo ao estudo da tradição latina do «Livro de Isaac»: o cód. ALC 387 da Biblioteca Nacional de Lisboa. Scripta Philologica, Feira de Santana, v. 1, p. 1-10, 2005.

CAMBRAIA, C. N. Livro de Isaac (cód. 50-2-15 da BN): caminhos percorridos. Anais da Biblioteca Nacional, Rio de Janeiro, v. 133-134, p. 15-35, 2015. 
CAMBRAIA, C. N.; AVELLAR, J. B. de C. Um ensaio de estemática: tradição ibero-românica da obra de Isaac de Nínive. Revista da ABR ALIN, Curitiba, v. 16, p. 15-36, 2017.

CÂNDOLO, T. Desejo de Deus: as lágrimas e a representação do ideal monástico primitivo em hagiografias medievais portuguesas. 432 f. 2002. Tese (Doutorado em Teoria e História Literária) - Instituto de Estudos da Linguagem, Universidade de Campinas, Campinas, 2002.

CHIALÀ, S. Dall'ascesi eremitica alla misericordia infinita: ricerche su Isaaco di Ninive e la sua fortuna. Firenze: Leo S. Olschki, 2002.

FRÄNKEL, H. Testo critico e critica del testo. 2. ed. ampl. Firenze: Le Monnier, 1983.

METZGER, B. M. The text of the new testament its transmission, corruption, and restoration. 3. ed. enlarg. New York/Oxford: Oxford University Press, 1992.

PETSCHENIG, M. (Ed.). Iohannis Cassiani Conlationes XXIIII. Vindobonae [Wien]: C. Geroldi, 1886. (Corpus Scriptorum Ecclesiaticorum Latinorum, XIII)

REYNOLDS, L. D.; WILSON, N. G. Copistas y filólogos. 2. ed. Madrid: Gredos, 1995.

SILVA, V. B. da. A ascese nas conferências de João Cassiano: fundamento para um discipulado florescente. 178 f. 2014. Dissertação (Mestrado em Teologia) - Faculdade Jesuíta de Filosofia e Teologia, 2014.

WENSINCK, A. J. (Tr.). Mystic treatises by Isaac of Nineveh. Wiesbaden: Martin Sändig oHG., 1969.

WEST, M. L. Crítica textual e técnica editorial aplicável a textos gregos e latinos. Lisboa: Fundação Calouste Gulbenkian, 2002. 